\title{
Prediction of Blasting Fragmentation Based on GWO-ELM
}

\author{
Zhengzhao Jia $\mathbb{D},{ }^{1}$ Ziling Song, ${ }^{2}$ Junfu Fan $\mathbb{D},{ }^{3}$ and Juyu Jiang ${ }^{1}$ \\ ${ }^{1}$ College of Mining, Liaoning Technical University, Fuxin, Liaoning 123000, China \\ ${ }^{2}$ College of Environment, Liaoning Technical University, Fuxin, Liaoning 123000, China \\ ${ }^{3}$ College of Mining, Inner Mongolia University of Technology, Hohhot, Inner Mongolia 010000, China \\ Correspondence should be addressed to Zhengzhao Jia; jzz19940201@163.com and Junfu Fan; junfufan@163.com
}

Received 24 September 2021; Revised 14 December 2021; Accepted 21 December 2021; Published 30 January 2022

Academic Editor: Xuesheng Liu

Copyright (C) 2022 Zhengzhao Jia et al. This is an open access article distributed under the Creative Commons Attribution License, which permits unrestricted use, distribution, and reproduction in any medium, provided the original work is properly cited.

\begin{abstract}
Aiming at the complex nonlinear relationship among factors affecting blasting fragmentation, the input weight and hidden layer threshold of ELM (extreme learning machine) were optimized by gray wolf optimizer (GWO) and the prediction model of GWOELM blasting fragmentation was established. Taking No. 2 open-pit coal mine of Dananhu as an example, seven factors including the rock tensile strength, compressive strength, hole spacing, row spacing, minimum resistance line, super depth, and specific charge are selected as the input factors of the prediction model. The average size of blasting fragmentation X50 is selected as the output factor of the prediction model and compared with the results of PSO-ELM and ELM. The results show that MAPE of GWO-ELM, PSO-ELM, and ELM are $1.78 \%, 5.40 \%$, and 10.90\%, respectively; their RMSE are 0.007, 0.022, and 0.045, respectively. The ELM model optimized by the gray wolf optimizer is more accurate and has stronger data fitting ability than PSO-ELM and ELM models, and the prediction accuracy of GWO-ELM is much higher than that of PSO-ELM and ELM.
\end{abstract}

\section{Introduction}

It is of great theoretical and practical significance to study the fragmentation distribution of rock blasting. Accurate prediction of fragmentation is of guiding value to the optimization of blasting parameters $[1,2]$. On the one hand, the size and distribution of blasting blocks are the important basis to judge the blasting effect; on the other hand, the analysis of rock blasting fragmentation distribution is an important way to further study blasting fragmentation mechanism and optimize blasting parameters. Scholars at home and abroad have put forward many theoretical models for the prediction of blasting fragmentation. The classical models include Kuz-Ram model and Rosin-Rammer model [3-5]. Because blasting is a complex nonlinear process, these classical theoretical models are based on certain assumptions and consider few influencing factors, so they all have certain limitations [6-9].

With the rapid development of artificial intelligence technology, using the powerful processing ability of computer to analyze the complex nonlinear process of blasting has been widely used, such as BP neural network, support vector machine, and GEP [4, 10-15]. Hasanipanah [16] proposed a new model for forecasting the rock fragmentation using adaptive neuro-fuzzy inference system (ANFIS) in combination with particle swarm optimization (PSO) [17-19]. Hasanipanah [16] proposed the rock engineering system (RES) technique to evaluate the risk associated with rock fragmentation as well as its prediction at Sarcheshmeh Copper Mine [16]. Hasanipanah et al. [20] developed a precise and applicable model based on regression tree (RT) to predict blast-produced flyrock distance in Ulu Tiram quarry, Malaysia [20]. Hasanipanah et al. [21] developed a precise equation for predicting flyrock through particle swarm optimization (PSO) approach [21]. Hasanipanah et al. [22] developed a novel hybrid artificial neural network (ANN) based on the adaptive musical inspired optimization method to predict blast-induced flyrock [22]. Hasanipanah and Bakhshandeh Amnieh [23] developed a fuzzy rock engineering system (FRES) framework to efficiently evaluate the parameters that affect flyrock [23]. Hasanipanah et al. [22] proposed a new uncertain rule-based fuzzy approach for the evaluation of blast-induced backbreak [24]. Zhu [25] presented a new hybrid model by combining chaos recurrent 
adaptive neuro-fuzzy inference system (CRANFIS) and particle swarm optimization (PSO) to predict ground vibration [25]. Fattahi and Hasanipanah [26] developed a new integrated intelligent model to approximate flyrock based on an adaptive neuro-fuzzy inference system (ANFIS) in combination with a grasshopper optimization algorithm (GOA) [26]. Dhal and Azad [27] proposed a binary version of the hybrid two-phase multiobjective FS approach, based on particle swarm optimization (PSO) and gray wolf optimization (GWO) $[27,28]$.

In addition, many experts at home and abroad have done a lot of research on blasting prediction and calculation. Wang et al. [29] proposed an improved VCCS algorithm based on discrete features to solve the segmentation problem of 3D LPCD of small blast muck piles, which cannot be effectively segmented and thus greatly influence the $3 \mathrm{D}$ LPCD of large blast muck piles [29, 30]. By further demonstrating that the impact of brittleness on fragmentation is physically inherent in the material dimension, we present new mechanistic insights into the blast-induced rock fragmentation via integrated analytical modelling, finite element simulation, and image processing [31, 32]. Yan et al. [33] present a new approach based on the three-dimensional distinct element code (3DEC) method to model the dynamic cracking and casting process of bench blasting with reasonable consideration of blasting fragmentation size.

ELM is a single hidden layer forward neural network with fast learning speed and strong generalization ability $[34,35]$. However, because the algorithm randomly generates input weights and hidden layer thresholds, its stability is poor. The learning effect is significantly affected by the number of hidden layer nodes [2, 36-44].

Therefore, this paper uses GWO to optimize the ELM input weights and hidden layer thresholds to improve the stability and prediction accuracy of the ELM model, so as to establish the GWO-ELM blasting fragmentation prediction model.

\section{Research Methods}

2.1. Extreme Learning Machine. Traditional extreme learning machine is a single hidden layer forward neural network; it consists of an input layer, a hidden layer, and an output layer; after initialization, the weights between the input layer and the hidden layer and the threshold of the hidden layer are random and fixed. In the case of determining the relevant parameters, the weight between the hidden layer and the output layer is calculated using the training sample, so as to complete the sample learning.

Considering there are $k$ different training samples, the input matrix $X$ and the output matrix $Y$ of the extreme learning machine are as follows:

$$
\begin{aligned}
\left(x_{i}, y_{i}\right), \quad x_{i} & =\left[x_{1 i}, x_{2 i}, \ldots, x_{n i}\right]^{T}, \\
y_{i} & =\left[y_{1 i}, y_{2 i}, \ldots, y_{n i}\right]^{T}, \quad(i=1,2, \ldots, K) .
\end{aligned}
$$

The activation function of the hidden layer is determined as $f(x)$; the number of hidden layer nodes is $L$, then the output value of training samples of the extreme learning machine can be expressed as,

$$
t_{j}=\sum_{i=1}^{l} \beta_{i} f\left(\omega_{i} x_{j}+b_{i}\right)(j=1,2, \ldots K),
$$

where $\beta_{i}$ is the output weight between the neuron in the hidden layer and the output factor in the output layer, $\omega_{i}$ is the input factor of the input layer and the neuron in the hidden layer, and $b_{i}$ is the threshold of hidden layer neurons.

The existence of $\beta_{i}, \omega_{i}$, and $b_{i}$ makes the output value of training samples infinitely close to the expected output, see below:

$$
\sum_{j=1}^{K} t_{j}-y_{j}=0
$$

Equation (3) can be simplified as,

$$
H \beta=Y \text {. }
$$

When the expected output and the output matrix are determined, the output weight is obtained by solving the least square solution of the linear equations:

$$
\widehat{\beta}=H^{+} Y \text {. }
$$

Here, $\mathrm{H}^{+}$is the Moore-Penrose generalized inverse matrix of the matrix $H$ of the hidden layer.

\subsection{GWO Optimized Extreme Learning Machine}

2.2.1. Gray Wolf Optimization Algorithm. Gray wolf optimization algorithm is a new metaheuristic swarm intelligence algorithm. Related researches show that it performs well in finding optimal solutions and the algorithm is simple. Gray wolf algorithm simulates the strict social hierarchy of wolves in nature, as shown in Figure 1. The first layer is the head wolf (denoted as $\alpha$ wolf), and the individuals in the lower layer are $\beta$ wolf, $\gamma$ wolf, and $\omega$ wolf, respectively.

(1) Surrounded by Prey. When the gray wolf algorithm attacks the prey, it firstly surrounds the prey, and its mathematical model can be expressed as the following equations:

$$
\begin{aligned}
D & =\left|C \cdot X_{p}(t)-X(t)\right|, \\
X(t+1) & =X_{p}(t)-A \cdot D .
\end{aligned}
$$

In equations (6) and (7), $t$ represents the number of iterations, and $X$ and $X_{p}$ represent the positions of gray wolves and prey, respectively. The coefficient vectors are $A$ and $C$, and the calculation formulas are shown in the following equations:

$$
\begin{aligned}
& A=2 \cdot a \cdot r_{1}-a, \\
& C=2 \cdot r_{2},
\end{aligned}
$$

where $A$ is the weighting factor, it is decreasing linearly from 2 to 0 , and $r_{1}$ and $r_{2}$ are a random number $(0,1)$. 


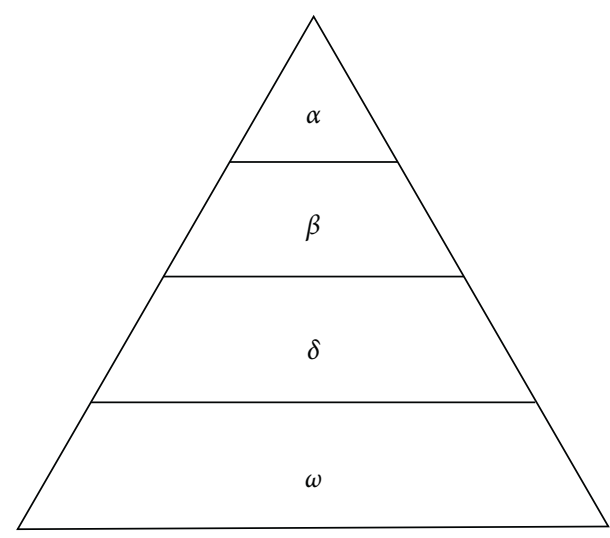

FIgURE 1: Classification of wolves.

(2) Hunting Behavior. After surrounding the prey, the wolf can locate the prey wherever it is and hunt after it, but this does not mimic the intelligent social behavior of the wolf. According to the characteristics of social rank, the optimal solution is $\alpha$; the suboptimal solution, the third optimal solution, and other individuals are denoted as $\beta, \gamma$, and $\omega$, respectively. The $\omega$ gray wolf updates its position according to the top three wolves, as shown in the formula below:

$$
\begin{aligned}
D_{\alpha} & =\left|C \cdot X_{\alpha}(t)-X(t)\right|, \\
X_{1} & =X_{\alpha}(t)-A_{1} \cdot D_{\alpha}, \\
D_{\beta} & =\left|C \cdot X_{\beta}(t)-X(t)\right|, \\
X_{2} & =X_{\beta}(t)-A_{2} \cdot D_{\beta}, \\
D_{\gamma} & =\left|C \cdot X_{\gamma}(t)-X(t)\right|, \\
X_{3} & =X_{\gamma}(t)-A_{3} \cdot D_{\gamma}, \\
X(t+1) & =\frac{\left(X_{1}+X_{2}+X_{3}\right)}{3} .
\end{aligned}
$$

(3) Attack Prey. The final stage of the gray wolf algorithm is to attack the prey, so as to find the optimal solution. The algorithm's optimization process is mainly realized by changing $A$ according to the decreasing of $a$ in formula (8). Then, the prey is hunted according to equations (10)-(13), and finally the prey is attacked.

2.2.2. GWO-ELM Arthmetic. Aiming at the problem that the input weights and hidden layer thresholds generated randomly during ELM algorithm training lead to poor prediction effect and stability, the global search ability of the algorithm is used to solve the optimal input weights and hidden layer thresholds. The root mean square error between the output value of training samples and the expected output value is used as the fitness function of GWO algorithm to improve the prediction accuracy of ELM. Its algorithm flow is shown in Figure 2.

\section{Blasting Fragmentation Prediction Model Based on GWO-ELM}

3.1. Field Investigation. The No. 2 open-pit coal mine of Dananhu is located in Hami City, Xinjiang Uygur Autonomous Region, with an annual output of 6 million tons. Coal mine is located in the northwest of the mining area, with a strike length of $6.21 \mathrm{~km}$, a slope width of $6.19 \mathrm{~km} \sim 6.88 \mathrm{~km}$, and an area of $40.52 \mathrm{~km}^{2}$. The coal mine is located in the remnant hill area, the remnant hills are low and scattered, the tops are round, the relative height difference is not large, the dry valleys are wide, the platform surface is relatively flat, and the ground surface is covered by residual and sloping rock debris layers. There is no surface water system within $50 \mathrm{~km}$ of the mining area and other surrounding areas. The altitude of the area is $+413.79 \mathrm{~m} \sim+569.50 \mathrm{~m}$, the lowest point is near the ZK10-3 hole in the south central part of the mine field, and the highest point is located in the northwest part of the mine field. The terrain is generally high in the north and west and low in the middle and southeast. The topography has a maximum elevation difference of $155.71 \mathrm{~m}$ and a slope of 15-30 degrees. It belongs to a low mountain and hilly area.

The spontaneous combustion of coal seams in the mining area causes the rock series and surrounding rocks above the coal seam to burn and bake, making the rocks with plastic deformation characteristics brittle and fragile. The rock mass has a fragmented structure, and the structure is in the form of flakes, plates, fragments, wedges, and rhombuses. The nearer the roof of the burning coal seam, the rock morphology appears as molten rock, which is characterized by locally developed tiny pore structures. The overall igneous rock section is dominated by red tones, followed by variegated colors such as light yellow, yellow, and gray.

3.2. The Determination of the Factors Affecting the Lumpiness. There are many factors affecting blasting fragmentation, which are mainly related to rock mechanical properties, blasting parameters, and charging technology. According to the previous experience and the actual situation of the site, seven main factors affecting the fragmentation were selected as the input factors of the prediction model, including rock tensile strength, rock compressive strength, hole spacing and row spacing, minimum resistance line, ultra-depth, and unit consumption of explosive. The average size of blasting fragmentation $X_{50}$ was selected as the output factor of the prediction model. By using GWO-ELM to deal with nonlinear mapping, the prediction model of bench blasting fragmentation distribution is established.

3.3. Parameter Selection. Initialize the gray wolf algorithm and select the appropriate parameters, parameter selection 40 , inertia weight $\omega=8$, the maximum number of iterations $T=300$, and the learning factors $C 1, C 2$ are $C 1=C 2=1.5$.

3.4. GWO-ELM Application of the Model. Due to the mismatch between blasting fragmentation and shoveling equipment, equipment wear is aggravated, which seriously 


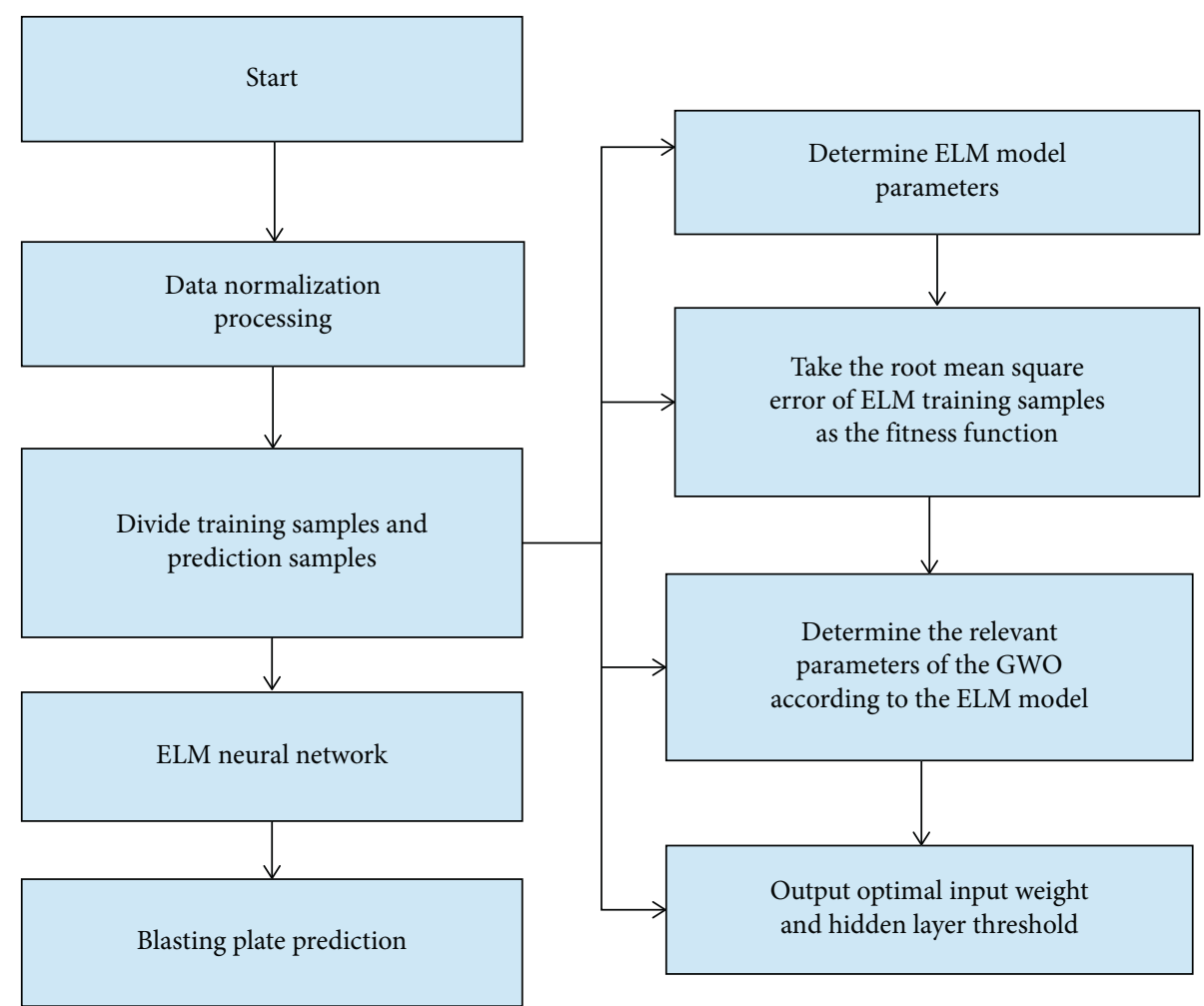

Figure 2: GWO-ELM algorithm flow.

TABLE 1: Model training samples and prediction samples.

\begin{tabular}{|c|c|c|c|c|c|c|c|c|}
\hline $\begin{array}{l}\text { Sample } \\
\text { sequence }\end{array}$ & $\begin{array}{c}\text { Tensile } \\
\text { strength } \\
\mathrm{MPa}\end{array}$ & $\begin{array}{c}\text { Compressive } \\
\text { strength } \\
\mathrm{MPa}\end{array}$ & $\begin{array}{l}\text { Blast hole } \\
\text { distance } \\
\mathrm{m}\end{array}$ & $\begin{array}{c}\text { Row } \\
\text { spacing } \\
\mathrm{m}\end{array}$ & $\begin{array}{l}\text { Minimum } \\
\text { resistance line } \\
\mathrm{m}\end{array}$ & $\begin{array}{l}\text { Super } \\
\text { deep } \\
\mathrm{m}\end{array}$ & $\begin{array}{c}\text { Unit } \\
\text { consumption } \\
\left(\mathrm{kg} \bullet \mathrm{m}^{-3}\right)\end{array}$ & $\begin{array}{c}\text { Average blasting } \\
\text { size } X_{50} \\
\text { m }\end{array}$ \\
\hline 1 & 5.6 & 45.6 & 6.5 & 3.5 & 3.2 & 1 & 0.59 & 0.76 \\
\hline 2 & 6.7 & 50.3 & 6.5 & 3.5 & 2.8 & 1.5 & 0.54 & 0.67 \\
\hline 3 & 4.8 & 46.4 & 7 & 3.5 & 2.4 & 1.2 & 0.57 & 0.47 \\
\hline 4 & 5.4 & 53.4 & 7 & 3.5 & 3.2 & 1.5 & 0.55 & 0.72 \\
\hline 5 & 7.4 & 57.6 & 7 & 3.5 & 2.7 & 1 & 0.52 & 0.81 \\
\hline 6 & 5.9 & 48.7 & 6 & 3 & 3.4 & 1.2 & 0.58 & 0.79 \\
\hline 7 & 5.4 & 49.5 & 6 & 3 & 3.3 & 1.5 & 0.55 & 0.72 \\
\hline 8 & 6.4 & 54.6 & 6 & 3 & 2.7 & 1 & 0.48 & 0.62 \\
\hline 9 & 6.2 & 42.6 & 6.2 & 3.5 & 2.9 & 1 & 0.54 & 0.59 \\
\hline 10 & 6.3 & 52.4 & 6.2 & 3.5 & 2.4 & 1 & 0.49 & 0.54 \\
\hline 11 & 6.9 & 56.7 & 6.5 & 3.5 & 2.4 & 1 & 0.59 & 0.66 \\
\hline 12 & 6.4 & 50.3 & 6.5 & 3.5 & 2.6 & 1.2 & 0.56 & 0.63 \\
\hline 13 & 4.9 & 53 & 6.2 & 3.5 & 3 & 1.5 & 0.54 & 0.66 \\
\hline 14 & 5 & 48.6 & 7 & 3.5 & 2.7 & 1.5 & 0.49 & 0.58 \\
\hline 15 & 7.1 & 58.4 & 6 & 3 & 2.6 & 1 & 0.47 & 0.72 \\
\hline 16 & 7 & 54.6 & 6.2 & 3.5 & 2.8 & 1 & 0.56 & 0.71 \\
\hline 17 & 5.2 & 52.4 & 6.5 & 3.5 & 2.5 & 1.5 & 0.52 & 0.49 \\
\hline 18 & 5.3 & 51.4 & 6 & 3 & 2.2 & 1.5 & 0.59 & 0.46 \\
\hline 19 & 6.1 & 52.8 & 7 & 3.5 & 3.4 & 1.5 & 0.49 & 0.76 \\
\hline 20 & 6.7 & 51.6 & 6.2 & 3.5 & 3.1 & 1.5 & 0.59 & 0.74 \\
\hline
\end{tabular}

affects the efficiency of shoveling and restricts economic benefits. Therefore, it is necessary to predict the average size of blasting lumpiness size $X_{50}$. This guides the optimization of blasting parameters, ensures the matching of blasting block degree and shovel equipment, and improves the production efficiency. 20 groups of blasting data measured in No. 2 open-pit coal mine of Dananhu (see Table 1) were selected, 15 groups were randomly selected as training samples (1-15 groups), and the remaining 5 groups were used as prediction samples (15-20 groups). All samples are normalized before input into the model. 


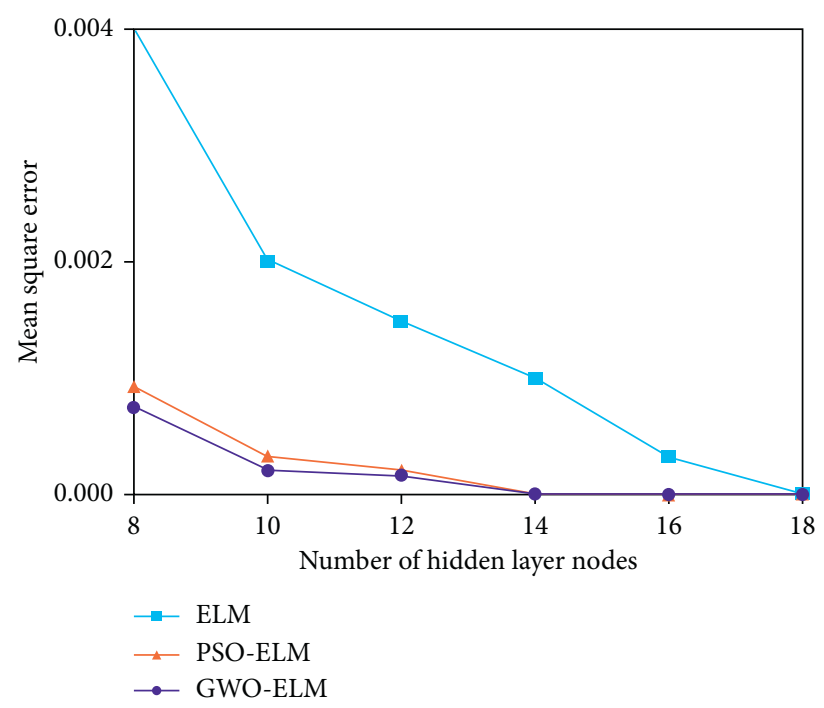

FIgURE 3: The relationship between the mean square error of the sample and the number of nodes in the hidden layer.

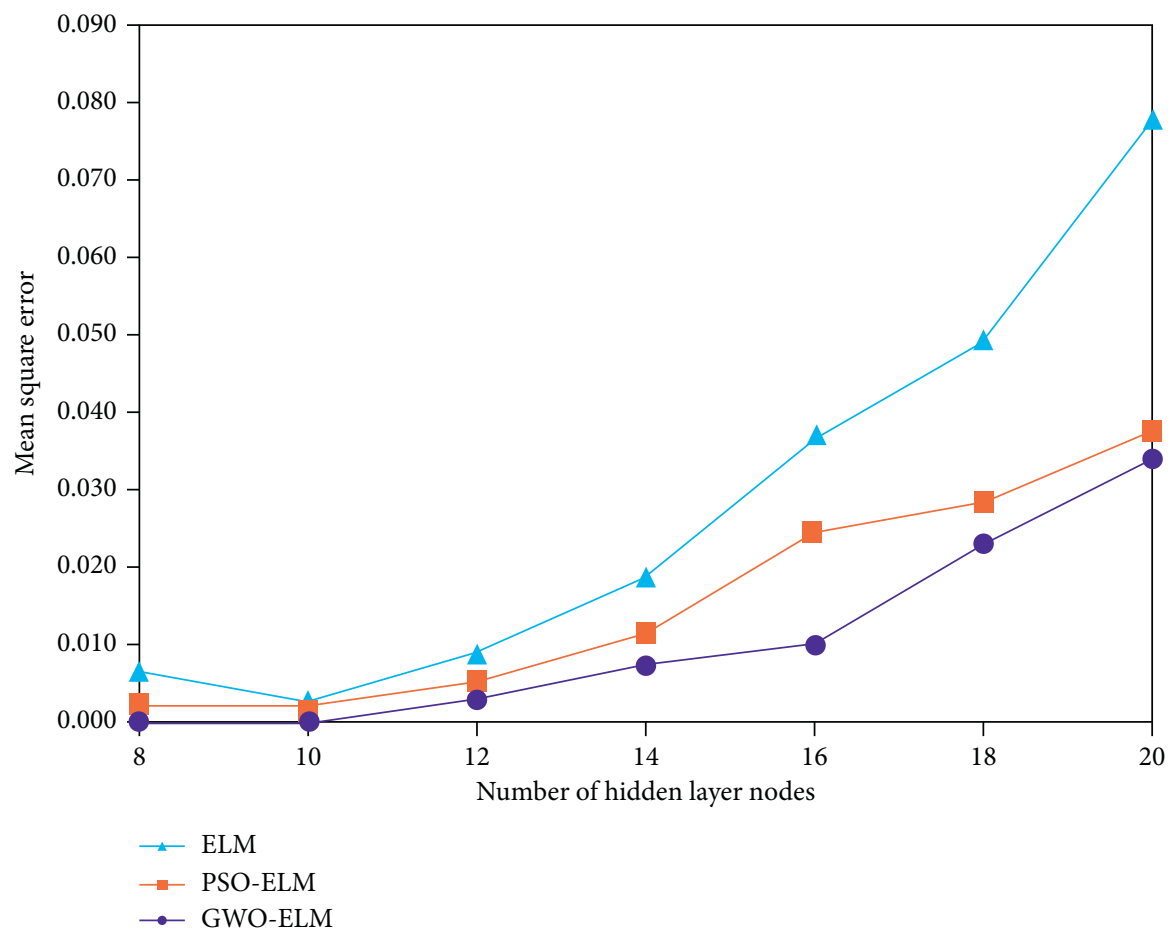

FIgURE 4: The relationship between the mean square error value of the prediction sample and the number.

3.5. Results Analysis. Since the number of hidden layer nodes will affect the training and prediction effects of ELM, this paper selects the best hidden layer nodes through trial and error method. We set $8,10,12,14,16,18$, and 20 hidden layers in GWO-ELM model, PSO-ELM, and ELM model, respectively, for training and prediction. The relationship between the mean square error of the training and prediction samples and the node changes of the hidden layer is shown in Figures 3 and 4. It can be seen that the number of hidden layer nodes has a significant impact on the training and prediction of samples, and the training error decreases with the increase of the number of hidden layer nodes until the error is zero. When the number of hidden layer nodes is small, the prediction accuracy is better. With the increase of hidden layer, the prediction error increases sharply with the increase of hidden layer nodes, which is because the error becomes larger due to overfitting. In conclusion, the ELM model optimized by gray wolf is less sensitive to the number of hidden layer nodes and more stable. When the number of hidden layers is the same, the training and prediction effects 


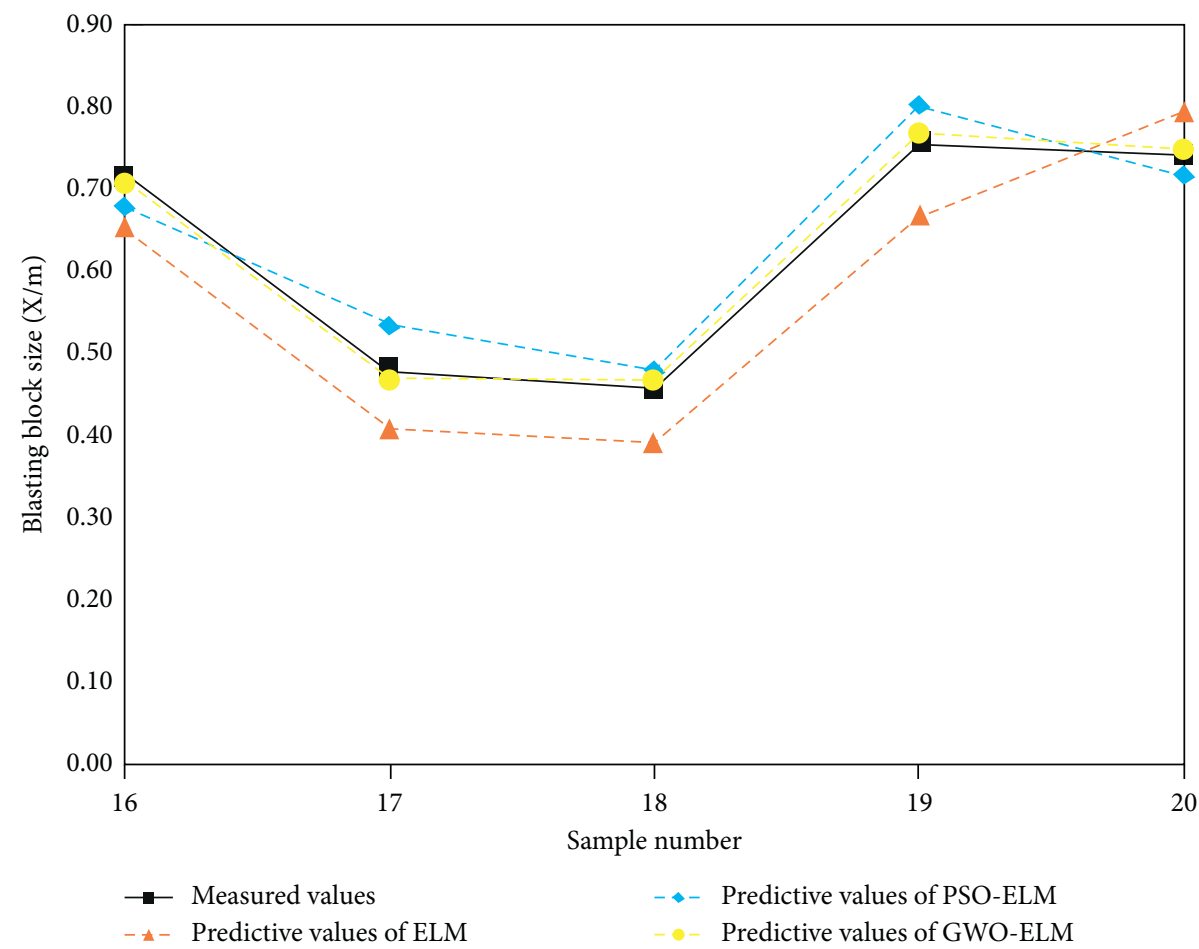

Figure 5: Comparison of model predicted value and measured value.

TABLE 2: Model comparison of predictive values and measured values of average size of blasting block $X_{50}$.

\begin{tabular}{|c|c|c|c|c|c|c|c|c|c|c|}
\hline \multirow{2}{*}{$\begin{array}{c}\text { Sample } \\
\text { sequence }\end{array}$} & \multirow{2}{*}{$\begin{array}{c}\text { Measured } \\
\text { values }\end{array}$} & \multicolumn{3}{|c|}{ Predictive value } & \multicolumn{3}{|c|}{ Absolute error } & \multicolumn{3}{|c|}{ Relative error } \\
\hline & & GWO-ELM & PSO-ELM & ELM & GWO-ELM & PSO-ELM & ELM & $\begin{array}{c}\text { GWO-ELM } \\
(\%)\end{array}$ & PSO-ELM & ELM \\
\hline 16 & 0.71 & 0.71 & 0.68 & 0.66 & 0 & 0.03 & 0.05 & 0 & $4.23 \%$ & $7.35 \%$ \\
\hline 17 & 0.49 & 0.47 & 0.54 & 0.42 & 0.02 & 0.05 & 0.07 & 4.08 & $10.64 \%$ & $12.96 \%$ \\
\hline 18 & 0.46 & 0.47 & 0.48 & 0.39 & 0.01 & 0.02 & 0.07 & 2.17 & $4.26 \%$ & $14.58 \%$ \\
\hline 19 & 0.76 & 0.77 & 0.8 & 0.67 & 0.01 & 0.04 & 0.09 & 1.32 & $5.19 \%$ & $11.25 \%$ \\
\hline 20 & 0.74 & 0.75 & 0.72 & 0.8 & 0.01 & 0.02 & 0.06 & 1.35 & $2.67 \%$ & $8.33 \%$ \\
\hline Min & $\mathrm{N} / \mathrm{A}$ & $\mathrm{N} / \mathrm{A}$ & $\mathrm{N} / \mathrm{A}$ & $\mathrm{N} / \mathrm{A}$ & 0 & 0.02 & 0.05 & 0 & $2.67 \%$ & $7.35 \%$ \\
\hline Max & N/A & N/A & N/A & N/A & 0.02 & 0.05 & 0.09 & 4.08 & $10.64 \%$ & $14.58 \%$ \\
\hline Mean & $\mathrm{N} / \mathrm{A}$ & $\mathrm{N} / \mathrm{A}$ & $\mathrm{N} / \mathrm{A}$ & $\mathrm{N} / \mathrm{A}$ & 0.01 & 0.032 & 0.068 & 1.78 & $5.40 \%$ & $10.90 \%$ \\
\hline RMSE & $\mathrm{N} / \mathrm{A}$ & $\mathrm{N} / \mathrm{A}$ & $\mathrm{N} / \mathrm{A}$ & N/A & 0.007 & 0.022 & 0.045 & $\mathrm{~N} / \mathrm{A}$ & $\mathrm{N} / \mathrm{A}$ & N/A \\
\hline
\end{tabular}

of GWO-ELM model are better than those of PSO-ELM and ELM model. In this paper, the number of hidden layers for GWO-ELM, PSO-ELM, and ELM to reach the best prediction is 10 .

Root mean square error (RMSE) and mean absolute percentage error (MAPE) were adopted to quantify the error of the predictive model and accuracy $[2,34,35]$, which are given by,

$$
\begin{aligned}
\text { RMSE } & =\sqrt{\frac{1}{N} \sum_{i=1}^{N}\left(x_{i}-y_{i}\right)^{2},} \\
\text { MAPE } & =\frac{1}{N} \sum_{i=1}^{N}\left|x_{i}-\frac{y_{i}}{x_{i}}\right|
\end{aligned}
$$

where $x_{i}$ denotes the measured values; $y_{i}$ denotes the predictive values; and $N$ denotes the number of predictors.
As shown in Figure 5 and Table 2, the minimum absolute errors of GWO-ELM, PSO-ELM, and ELM are 0, 0.02, and 0.05 ; their minimum relative errors are $0,2.67 \%$, and $7.35 \%$, respectively; the maximum absolute errors of GWO-ELM, PSO-ELM, and ELM are 0.02, 0.05, and 0.09; their maximum relative errors are $4.08 \%, 10.64 \%$, and $14.58 \%$, respectively; their MAPE are $1.78 \%, 5.40 \%$, and $10.90 \%$, respectively; their RMSE are $0.007,0.022$, and 0.045 , respectively. In conclusion, the ELM model optimized by the gray wolf algorithm is more accurate and has stronger data fitting ability than PSO-ELM and ELM models, and the prediction accuracy of GWO-ELM is much higher than that of PSO-ELM and ELM.

\section{Conclusion}

(1) In this paper, seven factors including rock tensile strength, rock compressive strength, blasthole spacing, row spacing, minimum resistance line, 
ultradeep, and explosive consumption are selected as input factors of the prediction model. The average size X50 of blasting fragmentation is selected as the output factor of the prediction model, and the GWO-ELM blasting fragmentation prediction model is established. The average relative error of prediction is $1.8 \%$, which is better than $5.6 \%$ of the PSP-ELM model and $11.4 \%$ of the ELM model. The prediction accuracy is high, which has certain guiding significance for the optimization of blasting parameters in open-pit coal mines. When the number of hidden layers is the same, the training and prediction effects of GWO-ELM model are better than those of PSO-ELM and ELM model. The best hidden layer node 10 in this paper is trained and predicted with GWO-ELM, PSO-ELM, and ELM, respectively.

(2) MAPE of GWO-ELM, PSO-ELM, and ELM are $1.78 \%, 5.40 \%$, and $10.90 \%$, respectively; their RMSE are $0.007,0.022$, and 0.045 , respectively. In conclusion, the ELM model optimized by the gray wolf algorithm is more accurate and has stronger data fitting ability than PSO-ELM and ELM models, and the prediction accuracy of GWO-ELM is much higher than that of PSO-ELM and ELM.

(3) Combining the gray wolf optimizer with the extreme learning machine, it is applied to the prediction of blasting fragmentation. The prediction effect is good and the stability is high. It has a certain reference value to the practice of similar prediction engineering. Generally speaking, a large amount of data is required to perform data through machine learning methods. The amount of blasting data in this article is small and cannot reflect the blasting predictions of different mining areas. Therefore, in the follow-up research, we need to expand the amount of our forecasting data and then continuously improve the forecasting ability of the model.

\section{Data Availability}

The data used to support the findings of this study are included in the article.

\section{Conflicts of Interest}

The authors declare that they have no conflicts of interest.

\section{Acknowledgments}

This project was supported by the National Natural Science Foundation of China, Integrated Technology of Ecological Environment Restoration and Mining in Open Pit Coal Mine Based on Green Degree, Project Grant no. 51474119.

\section{References}

[1] M. Monjezi and H. Dehghani, "Evaluation of effect of blasting pattern parameters on back break using neural networks,"
International Journal of Rock Mechanics and Mining Sciences, vol. 45, no. 8, pp. 1446-1453, 2008.

[2] M. Khandelwal and M. Monjezi, "Prediction of backbreak in open-pit blasting operations using the machine learning method," Rock Mechanics and Rock Engineering, vol. 46, no. 2, pp. 389-396, 2013.

[3] Z. Hongliang, W. Shuilin, L. Yinghui, and Y. Xiaotao, "Analysis and Forecast of Basting Vibration Effect Based on Support Vector Machine," Mining Research and Development, vol. 4, 2007.

[4] W. Tingxin, C. Xiaoyu, L. Tianyu, and L. Xu, "Predicting research on characteristic parameters of blast-induced vibration based on optimized IGA-ELM model," China Safety Science Journal, vol. 27, no. 11, pp. 37-42, 2017.

[5] Y. Zeng-De, W. Lai-He, and L. Yan-Ni, "Prediction of rockburst based on chaos particle swarm optimization BP neural network," Coal Technology, vol. 35, no. 8, pp. 89-91, 2016.

[6] B. Ji, F. Xie, X. Wang, S. He, and D. Song, "Investigate contribution of multi-microseismic data to rockburst risk prediction using support vector machine with genetic algorithm," IEEE Access, vol. 8, Article ID 58817, 2020.

[7] M. A. Morin and F. Ficarazzo, "Monte Carlo simulation as a tool to predict blasting fragmentation based on the Kuz-Ram model," Computers \& Geosciences, vol. 32, no. 3, pp. 352-359, 2006.

[8] P. González-Tello, F. Camacho, J. M. Vicaria, and P. A. González, "A modified Nukiyama-Tanasawa distribution function and a Rosin-Rammler model for the particlesize-distribution analysis," Powder Technology, vol. 186, no. 3, pp. 278-281, 2008.

[9] M. Hajihassani, D. Jahed Armaghani, H. Sohaei, E. Tonnizam Mohamad, and A. Marto, "Prediction of airblast-overpressure induced by blasting using a hybrid artificial neural network and particle swarm optimization," Applied Acoustics, vol. 80, pp. 57-67, 2014.

[10] L. Shuran and L. Shujin, "Applying BP neural network model to forecast peak velocity of blasting ground vibration," Procedia Engineering, vol. 26, pp. 257-263, 2011.

[11] P. Dey, A. Sarkar, and A. K. Das, "Development of GEP and ANN model to predict the unsteady forced convection over a cylinder," Neural Computing \& Applications, vol. 27, no. 8, pp. 2537-2549, 2016.

[12] M. R. Kaloop, D. Kumar, P. Samui et al., "Particle swarm optimization algorithm-extreme learning machine (PSO-ELM) model for predicting resilient modulus of stabilized aggregate bases," Applied Sciences, vol. 9, no. 16, p. 3221, 2019.

[13] Y. Zhang, Y. Xie, Y. Zhang, J. Qiu, and S. Wu, "The adoption of deep neural network (DNN) to the prediction of soil liquefaction based on shear wave velocity," Bulletin of Engineering Geology and the Environment, vol. 80, no. 6, pp. 5053-5060, 2021.

[14] Y. G. Zhang, J. Qiu, Y. Zhang, and Y. Wei, “The Adoption of ELM to the Prediction of Soil Liquefaction Based on CPT," Natural Hazards, vol. 107, 2021.

[15] Y. Zhang, J. Qiu, Y. Zhang, and Y. Xie, "The adoption of a support vector machine optimized by GWO to the prediction of soil liquefaction," Environmental Earth Sciences, vol. 80, no. 9, pp. 1-9, 2021.

[16] M. Hasanipanah, D. Jahed Armaghani, M. Monjezi, and S. Shams, "Risk assessment and prediction of rock fragmentation produced by blasting operation: a rock engineering system," Environmental Earth Sciences, vol. 75, no. 9, p. 808, 2016. 
[17] M. Hasanipanah, H. B. Amnieh, H. Arab, and M. S. Zamzam, "Feasibility of PSO-ANFIS model to estimate rock fragmentation produced by mine blasting," Neural Computing \& Applications, vol. 30, no. 4, pp. 1015-1024, 2018.

[18] A. Jain, D. Yadav, and A. Arora, "Particle swarm optimization for Punjabi Text summarization," International Journal of Operations Research and Information Systems, vol. 12, no. 3, pp. 1-17, 2021.

[19] E. Bas, E. Egrioglu, and E. Kolemen, "Training simple recurrent deep artificial neural network for forecasting using particle swarm optimization," Granular Computing, pp. 1-10, 2021, (prepublish).

[20] M. Hasanipanah, R. S. Faradonbeh, D. J. Armaghani, H. B. Amnieh, and M. Khandelwal, "Development of a precise model for prediction of blast-induced flyrock using regression tree technique," Environmental Earth Sciences, vol. 76, no. 1, pp. 1-10, 2017.

[21] M. Hasanipanah, D. Jahed Armaghani, H. Bakhshandeh Amnieh, M. Z. A. Majid, and M. M. D. Tahir, "Application of PSO to develop a powerful equation for prediction of flyrock due to blasting," Neural Computing \& Applications, vol. 28, no. S1, pp. 1043-1050, 2017.

[22] M. Hasanipanah, B. Keshtegar, D.-K. Thai, and N.-T. Troung, "An ANN-adaptive dynamical harmony search algorithm to approximate the flyrock resulting from blasting," Engineering with Computers, pp. 1-13, 2020.

[23] M. Hasanipanah and H. Bakhshandeh Amnieh, "A fuzzy rulebased approach to address uncertainty in risk assessment and prediction of blast-induced flyrock in a quarry," Natural Resources Research, vol. 29, no. 2, pp. 669-689, 2020.

[24] M. Hasanipanah and H. Bakhshandeh Amnieh, "Developing a new uncertain rule-based fuzzy approach for evaluating the blast-induced backbreak," Engineering with Computers, vol. 37, no. 3, pp. 1879-1893, 2021.

[25] W. Zhu, H. Nikafshan Rad, and M. Hasanipanah, "A chaos recurrent ANFIS optimized by PSO to predict ground vibration generated in rock blasting," Applied Soft Computing, vol. 108, Article ID 107434, 2021.

[26] H. Fattahi and M. Hasanipanah, "An integrated approach of ANFIS-grasshopper optimization algorithm to approximate flyrock distance in mine blasting," Engineering with Computers, pp. 1-13, 2021.

[27] P. Dhal and C. Azad, "A multi-objective feature selection method using Newton's law based PSO with GWO,” Applied Soft Computing, vol. 107, Article ID 107394, 2021.

[28] M. Banaie-Dezfouli, M. H. Nadimi-Shahraki, and Z. Beheshti, "R-GWO: Representative-based grey wolf optimizer for solving engineering problems," Applied Soft Computing, vol. 106, Article ID 107328, 2021.

[29] Y. Wang, W. Tu, and H. Li, "Fragmentation calculation method for blast muck piles in open-pit copper mines based on three-dimensional laser point cloud data," International Journal of Applied Earth Observation and Geoinformation, vol. 100, Article ID 102338, 2021.

[30] Z. Leng, Y. Fan, Q. Gao, and Y. Hu, "Evaluation and optimization of blasting approaches to reducing oversize boulders and toes in open-pit mine," International Journal of Mining Science and Technology, vol. 30, no. 3, pp. 373-380, 2020.

[31] J. Tao, X.-G. Yang, H.-T. Li, J.-W. Zhou, S.-C. Qi, and G.-Da Lu, "Numerical investigation of blast-induced rock fragmentation," Computers and Geotechnics, vol. 128, Article ID 103846, 2020.

[32] K. Manoj and M. Monjezi, "Prediction of flyrock in open pit blasting operation using machine learning method,"
International Journal of Mining Science and Technology, vol. 23, no. 3, pp. 313-316, 2013.

[33] Y. Peng, W. Zhou, W. Lu, M. Chen, and C. Zhou, "Simulation of bench blasting considering fragmentation size distribution," International Journal of Impact Engineering, vol. 90, pp. 132-145, 2016.

[34] J. Wang, S. Lu, S. H. Wang, and Y. D. Zhang, "A Review on Extreme Learning machine," Multimedia Tools and Applications, pp. 1-50, 2021.

[35] J. Duan, Y. Ou, J. Hu, Z. Wang, S. Jin, and C. Xu, "Fast and stable learning of dynamical systems based on extreme learning machine," IEEE Transactions on Systems, Man, and Cybernetics: Systems, vol. 49, no. 6, pp. 1175-1185, 2019.

[36] S. Du, G. Feng, J. Wang, S. Feng, R. Malekian, and Z. Li, “A new machine-learning prediction model for slope deformation of an open-pit mine: an evaluation of field data," Energies, vol. 12, no. 7, p. 1288, 2019.

[37] J. Dai and Y. Liu, "The Method of Optimizing Blasting Parameters for Driving Tunnel Based on the Outcome Analyses," Advanced Materials Research, Trans Tech Publications Ltd, vol. 243-249, , pp. 3449-3455, 2011.

[38] X. Liu, S. Song, Y. Tan et al., "Similar simulation study on the deformation and failure of surrounding rock of a large section chamber group under dynamic loading," International Journal of Mining Science and Technology, vol. 31, no. 3, 2021.

[39] Y. Sun, G. Li, N. Zhang, Q. Chang, J. Xu, and J. Zhang, "Development of ensemble learning models to evaluate the strength of coal-grout materials," International Journal of Mining Science and Technology, vol. 31, no. 2, pp. 153-162, 2021.

[40] A. I. Lawal, S. Kwon, O. S. Hammed, and M. A. Idris, "Blastinduced ground vibration prediction in granite quarries: an application of gene expression programming, ANFIS, and sine cosine algorithm optimized ANN," International Journal of Mining Science and Technology, vol. 31, no. 2, pp. 265-277, 2021.

[41] G. Wang, X. Qin, D. Han, and Z. Liu, "Study on seepage and deformation characteristics of coal microstructure by $3 \mathrm{D}$ reconstruction of CT images at high temperatures," International Journal of Mining Science and Technology, vol. 31, no. 2, pp. 175-185, 2021.

[42] W. Hou, H. Wang, L. Yuan, W. Wang, Y. Xue, and Z. Ma, "Experimental research into the effect of gas pressure, particle size and nozzle area on initial gas-release energy during gas desorption," International Journal of Mining Science and Technology, vol. 31, no. 2, pp. 253-263, 2021.

[43] Y.-g. Zhang, J. Tang, Z.-y. He, J. Tan, and C. Li, "A novel displacement prediction method using gated recurrent unit model with time series analysis in the Erdaohe landslide," Natural Hazards, vol. 105, no. 1, pp. 783-813, 2021.

[44] Y.-G. Zhang, J. Tang, R.-P. Liao et al., "Application of an enhanced BP neural network model with water cycle algorithm on landslide prediction," Stochastic Environmental Research and Risk Assessment, vol. 35, no. 6, pp. 1273-1291, 2021. 